\title{
Perioperative management of geriatric patients for orthopedic surgeries
}

\author{
Bhavya Krishna, Nidhi Pathak*
}

Department of Anesthesia, VMMC and Safdarjung Hospital, New Delhi, India

Received: 31 January 2020

Revised: 13 February 2020

Accepted: 15 February 2020

\section{*Correspondence:}

Dr. Nidhi Pathak,

E-mail: nidhipathak06@gmail.com

Copyright: () the author(s), publisher and licensee Medip Academy. This is an open-access article distributed under the terms of the Creative Commons Attribution Non-Commercial License, which permits unrestricted non-commercial use, distribution, and reproduction in any medium, provided the original work is properly cited.

\begin{abstract}
With increasing life expectancy, the mean age of patient orthopedicians and anesthesiologists have to deal with is increasing. In this review article, we discuss the case management of three centurions aged 110, 105 and 102 years respectively who underwent lower limb orthopedic surgery under nerve block, general anesthesia and neuraxial blockade, and elaborate on the various issues faced perioperatively by the treating team. The challenges and differences faced in perioperative period in geriatric anesthesia were discussed and literature reviewed for the benefit of the operating surgeons.
\end{abstract}

Keywords: Geriatric, Orthopedic, Fracture, Anesthesia

\section{INTRODUCTION}

With increasing life expectancy, both orthopedicians and anesthesiologists now have to be confident in handling geriatric cases. Geriatric patients aren't just old adults. They come with a myriad of problems specific to their age group. Geriatric anaesthesia for orthopedic surgeries combines the risk associated with old age like decreased functional capacity, multiple comorbidities, cognitive dysfunction, multiple medications and the complications of surgery per se like blood loss, difficult positioning, embolism etc, whereas from the surgeon's point of view they are prone to fractures, less muscle mass etc. ${ }^{1} \mathrm{We}$ hereby discuss the perioperative management of 3 elderly patients of age 100 and above: 110 years, 105 years and 102 years respectively.

\section{METHODS}

\section{Case report 1}

A 110 year old lady presented to us with neck of femur fracture and was planned for elective bipolar hemiarthroplasty. Appropriate anesthetic assessment was done and there was no positive history of any systemic illness except anemia (hemoglobin (Hb) $9 \mathrm{gm} \%$, hematocrit (HCT) 27\%). The rest of the investigations were within normal limits. On examination, she was pale, frail and had a kyphoscoliotic spine with intervertebral spaces not well felt. Her anemia was treated with packed cell transfusion preoperatively to attain $\mathrm{Hb}$ of $10 \mathrm{gm} \%$ and adequate blood products reserved for surgery. Plan of anesthesia was neuraxial anesthesia combined spinal and epidural (CSE). Several attempts were made to put CSE with changes tried in approach (median or paramedian), position change, provider, space and needle change. Secondary to calcifications, ossifications and kyphoscoliotic spine, neuraxial plan was abandoned and we proceeded with putting nerve blocks instead comprising of femoral and obturator and lateral cutaneous nerve of thigh and sciatic nerve block along with local anesthesia infiltration at proximal site of skin incision. ${ }^{2}$ After adequate effect surgery was started which lasted about two hours, with blood loss of $500 \mathrm{ml}$ and was replaced with one unit packed cell transfusion intraoperatively. Patient was discharged in 5 days after 
receiving physiotherapy and rehabilitation training and was asked to come for follow up for further management.

\section{Case report 2}

A 105 year old gentleman presented to us with shaft of femur fracture in the emergency department. He was a known case of CAD on antiplatelets (clopidogrel $75 \mathrm{mg}$ and aspirin $75 \mathrm{mg}$ ), hypertensive on beta blocker (atenolol $50 \mathrm{mg}$ ), uncontrolled diabetic with $\mathrm{HbA} 1 \mathrm{C}$ of $11 \%$ on irregular intake of oral hypoglycemic agents (OHA) with features of autonomic neuropathy (paresthesia in bilateral foot and postural hypotension). Cardiac consultation was taken with a screening echo showing ejection fraction of $60 \%$. On examination, he was edentulous. Since it was an emergency surgery, with adequate risk assessment and consent, he was taken up for surgery under high risk consent and general anesthesia administered since neuraxial blockade or nerve block couldn't be given due to the anticoagulated state. ${ }^{3}$ His international normalized ratio was 1.2 and platelet count $1.5 \mathrm{lacs} / \mathrm{mm}^{3}$. After giving judicious amount of opioid (inj fentanyl $1.5 \mu / \mathrm{kg}$ iv), titrated dose of etomidate $(0.3 \mathrm{mg} / \mathrm{kg}$ iv $)$ given followed by atracurium $(0.5 \mathrm{mg} / \mathrm{kg})$ muscle relaxant and a proseal laryngeal mask airway placed in a deep plane for mechanical ventilation using sevoflurane and nitrous oxide with oxygen gas mixture for maintenance. Hemodynamics were fluctuating intraoperatively for which appropriate drugs (variable doses of phenylephrine) and fluids were given. Normothermia was maintained. At the end of the surgery, neuromuscular blockade was reversed (inj glycopyrrolate $0.2 \mathrm{mg} / \mathrm{kg}$ iv and ing neostigmine $0.5 \mathrm{mg} / \mathrm{kg}$ ) and patient extubated once he was completely awake. He developed lower respiratory tract infection on post-operative day 3 probably secondary to being immobilised and in view of emergency surgery, there was no time for preoperative optimisation or incentive spirometry. Adequate antibiotics and respiratory care were given following which he recovered and was discharged in 8 days.

\section{Case report 3}

A 102 year old lady with neck of femur fracture was planned for open reduction internal fixation. She was hard of hearing. She had no other comorbidities or positive findings, and after taking consent from her and her attendants, she was taken up for surgery under neuraxial blockade (CSE was planned), avoiding parenteral opioids, benzodiazepines, and other anesthetic agents. After noting baseline monitor values, intravenous line secured and co loading was done with ringer lactate fluid. Low dose local anesthetic combined with opioid (2.4 $\mathrm{ml}$ of $0.5 \%$ hyperbaric bupivacaine with $0.2 \mathrm{ml}$ (10 $\mathrm{mcg}$ ) fentanyl) was given via paramedian approach through a 27G Quincke needle in the L3-4 intervertebral space (level achieved was dermatome level T10 with modified Bromage score 1 (complete block). ${ }^{4}$ Pressure point padding was done, efforts to maintain normothermia were taken. As the patient was hard of hearing, it was a challenge to keep counselling her intraoperatively. Although the surgery was uneventful, she developed postoperative cognitive dysfunction (POCD) a few days after surgery, despite taking all possible precautions. She was discharged on the 6th day after maximal optimisation.

\section{DISCUSSION}

Management of geriatric patients involves preoperative assessment for risk- stratification, intra operative management of comorbidities and complications and postoperative discharge planning. Even in the absence of a specific organ-based disease process, anaesthesia for the elderly requires an alteration in technique to take account of age-related changes to normal physiology as discussed in Table 1. These changes are even more pronounced in elderly aged above 100 years old.

\section{Pre operative assessment and management}

The preoperative management and assessment of a geriatric patient requires several factors to be kept in mind. ${ }^{5}$ Regular perioperative risk assessment measures may often overlook subtle geriatric-specific syndromes that translate into increased vulnerabilities for older patients. Although old age is not a disease, the age of the patient is the most important factor as there are physiological changes as given in Table 1. Several comorbidities are present in elderly - most commonly hypertension, diabetes, $\mathrm{CAD}$, cancer, and cerebrovascular disease. They should all be tackled individually, polypharmacy and drug interactions to be kept in mind. The extent and duration of surgery, planned technique of anaesthesia, blood products needed, expected postoperative care should all be discussed and adequate arrangements made. The patient's goals and treatment preferences, health care proxy or surrogate decisionmaker should all be confirmed and documented. In patients with existing advance directives, new risks associated with the surgical procedure and an approach for potentially life-threatening problems consistent with the patient's values and preferences should be discussed. Shortened fluid fast (clear liquids up to two hours before anesthesia) and solid fasting should be considered. Adherence to existing best practices regarding antibiotic and venous thromboembolism prophylaxis should be done. Nonessential medications should be stopped and only essential medications given. Incentive spirometry, deep breathing exercises should be started. Multidisciplinary approach with consultations from physical rehabilitation specialist, occupational therapy and post discharge home needs should be done.

\section{Counselling and consent in geriatric}

Cognitive dysfunctions, memory loss, hearing loss, dementia, depression and stroke may all complicate the issues of consent and decision making. Talking about legal standards of competence for consent include- the 
abilities to communicate a choice, understand relevant information, appreciate the current situation and its consequences, manipulate the information rationally. The above mentioned features are often not present in elderly patients, making counselling and consent a difficult task in them. In the 3 case reports mentioned above, only one patient had hearing problem but she was explained about the risk, procedure and complications with the help of her relatives and sign language.

Table 1: Physiological changes in geriatric age group. ${ }^{6}$

\begin{tabular}{|c|c|c|}
\hline System & Structural changes & Functional changes \\
\hline CNS & $\begin{array}{l}\text { - } \quad \downarrow \text { in volume of both gray and white } \\
\text { matter } \\
\text { Shrinkage of subcortical white matter } \\
\text { and hippocampus (more with } \\
\text { hypertension \& vascular disease) }\end{array}$ & $\begin{array}{ll}\text { - } & \text { Memory decline } \\
\text { - } & \downarrow \text { in neurotransmitters like dopamine, } \\
\text { - } & \text { acetylcholine, norepinephrine and serotonin } \\
\text { - } & \downarrow \text { in functional activity of daily life } \\
\text { - } & \uparrow \text { sensitivity to anaesthetic } \\
\text { - } & \text { medications } \\
\text { - } & \quad \text { risk of delirium } \\
\text { - } & \uparrow \text { risk of postoperative cognitive dysfunction }\end{array}$ \\
\hline $\begin{array}{l}\text { Neuraxial } \\
\text { changes }\end{array}$ & $\begin{array}{ll}\text { - } & \downarrow \text { in epidural space area } \\
\text { - } & \uparrow \text { permeability of dura } \\
\text { - } & \downarrow \text { volume of CSF } \\
\text { - } & \downarrow \text { diameter and number of myelinated } \\
& \text { fibers in dorsal and ventral nerve roots }\end{array}$ & $\begin{array}{l}\text { - } \quad \downarrow \text { conduction velocity } \\
\text { - All the structural and functional changes leads to } \\
\uparrow \text { sensitivity to neuraxial and peripheral nerve } \\
\text { blocks }\end{array}$ \\
\hline $\begin{array}{l}\text { Cardiovascular } \\
\text { system }\end{array}$ & $\begin{array}{l}\text { - } \quad \downarrow \text { myocyte number } \\
\text { - } \quad \downarrow \text { in conduction fiber density and } \\
\text { number of sinus node cells } \\
\text { - } \quad \downarrow \text { contractility } \\
\text { - } \quad \uparrow \text { myocardial stiffness and ventricular } \\
\text { filling pressure } \\
\text { - } \quad \uparrow \text { central aortic dilatation } \\
\text { - } \quad \uparrow \text { thickness of arterial wall } \\
\text { - } \quad \text { Aortic valve sclerosis and annular } \\
\quad \text { calcification }\end{array}$ & $\begin{array}{ll}\text { - } & \downarrow \beta \text { adrenergic sensitivity } \\
\text { - } \quad & \uparrow \text { in sympathetic nervous system activityà } \\
& \uparrow \text { systemic vascular resistance and mechanical } \\
& \text { stiffening of peripheral vessels } \\
\text { - } & \downarrow \text { maximal heart rate and } \downarrow \text { peak ejection fraction } \\
& \text { during exercise and stress which makes heart } \\
& \text { more susceptible to cardiac failure } \\
\text { - } & \text { Diastolic dysfunctionà diastolic heart failure }\end{array}$ \\
\hline $\begin{array}{l}\text { Respiratory } \\
\text { system }\end{array}$ & $\begin{array}{ll}\text { - } & \downarrow \text { elastic recoil } \\
\text { - } & \text { Altered surfactant } \\
\text { - } & \uparrow \text { in lung compliance } \\
\text { - } & \uparrow \text { in anatomic dead space } \\
\text { - } & \downarrow \text { diffusing capacity } \\
\text { - } & \uparrow \text { closing capacity } \\
\text { - } & \text { Impaired gas exchange } \\
\text { - } & \text { Residual volume } \uparrow \text { by } 5-10 \% \text { per } \\
& \text { decade } \\
\text { - } & \text { Vital capacity } \downarrow \\
\text { - } & \text { Functional Residual capacity - } \\
& \text { unchanged/ slightly } \uparrow\end{array}$ & $\begin{array}{l}\text { - } \quad \text { Ventricular response to hypoxia, hypercapnia and } \\
\text { mechanical stress impairment secondary to } \downarrow \\
\text { CNS activity } \\
\text { - } \quad \text { Respiratory depressant effect of benzodiazepines, } \\
\text { opioids and volatile anaesthetics } \\
\text { - } \quad \text { sensitivity for bronchoconstriction and } \\
\downarrow \text { response to treatment with inhaled } \beta \text { agonist } \\
\text { - } \quad \downarrow \text { immune response --> } \uparrow \text { susceptibility to } \\
\text { environment exposure and lung injury }\end{array}$ \\
\hline Renal & $\begin{array}{l}\text { - } \\
\quad \begin{array}{l}\text { Nephrosclerosis } \\
\text { decade }\end{array}\end{array}$ & - $\quad \downarrow$ renal capacity to conserve sodium is decreased \\
\hline Hepatic & $\begin{array}{l}\text { - Liver volume decreased by } 20-40 \% \\
\text { with aging } \\
\text { - Hepatic blood flow decreases } 10 \% \text { per } \\
\text { decade }\end{array}$ & - $\quad \downarrow$ in hepatic metabolism \\
\hline
\end{tabular}

\section{Intraoperative management}

\section{General considerations}

Preoperative antibiotics should be given based on procedure, risk factors, and the hospital's unique pathogen profile within 60 minutes before surgical incision. Consideration of regional techniques to avoid postoperative complications and improve pain control should be taken. There should be a detailed perioperative analgesic plan including taking a directed pain history and plan multi-modal or opioid-sparing techniques with 
consideration of regional techniques. Postoperative nausea risk stratification and prevention strategies should be taken. Prevention of postoperative pulmonary complications and hypothermia should be done. Appropriate use of intravenous fluids, restrictive or goaldirected strategies should be preferred over fixed-volume strategies, which can cause fluid overload in an already compromised physiological state in elderly. ${ }^{7}$ Appropriate hemodynamic management anticipating the fluctuations. Measures should be taken to ensure proper positioning and padding of bony prominences of elderly patients undergoing elective or nonelective surgery to maintain skin integrity and limit pressure on peripheral nerves and prevention of pressure ulcers. The elderly in particular are predisposed to hypothermia due to altered thermoregulation from decreased muscle mass, metabolic rate, and vascular reactivity. Patient warming with forced air warmers and/or warmed IV fluids should be used in older patients who are undergoing procedures longer than 30 minutes to avoid hypothermia. ${ }^{8}$

\section{Blood transfusion}

Orthopedic surgeries often require blood transfusion. ${ }^{9}$ There should be proper assessment of hemoglobin before surgery as it is seen that that patients with anemia have more risk of surgical complications and death especially during orthopedic surgeries because of the large quantities of blood loss due to bone trauma and the difficulties of achieving hemostasis in this tissue. If hemoglobin level is less than $6 \%$ the risk may increase up to $30 \%$. There occurs dramatic improvement in symptoms with small improvements in hemoglobin and hematocrit. In elective surgeries the recommended hemoglobin level is $11 \mathrm{~g} \%$. Talking about replacement, packed red blood cells seems to be most effective both during and after the procedure. But it has been found that infection rates are higher among patients undergoing femoral neck surgery who received transfusions because of decreased immunity. ${ }^{10}$

\section{ANESTHESIA IN ELDERLY}

\section{Nerve blocks}

There are several changes that occur in peripheral nervous system with respect to aging like peripheral nerve deterioration; dysfunction of genes responsible for myelin sheath protein components; decreased myelinated nerve fiber conduction velocity; motor and sensory discriminatory changes in the feet; changes in sensation (e.g. pain, touch).

Nerve blocks are considered safe in the elderly and are shown to have benefits in terms of faster post operative mobility as compared to epidural analgesia for lower limb surgeries. ${ }^{11}$ They also play an important role as a part of multi modal analgesia. Adequate pain management is of utmost importance in the elderly as enhances faster recovery by improving mobility, lesser postoperative respiratory complications, and lesser delirium.

\section{General anesthesia}

General anesthesia involves airway manipulation as well as administration of a cocktail of drugs, all of which are affected in the elderly.

Elderly patients are prone to structural and functional changes surrounding the airway, including, but not limited to, an edentulous mouth, oropharyngeal tumors, atrophy of the glottic muscles, and decreased neck range of movements as compared to a young adult making bag mask ventilation (BMV) and intubation more difficult. In case report 2 , the 105 year old adult was edentulous and had difficult BMV for which we used a gauze pack to cover the hollow cheeks. Laryngeal mask airway placement was however done without any difficulties. ${ }^{12}$ In addition, age-related comorbidities such as chronic obstructive pulmonary disease, gastroesophageal reflux disease, and diabetes increase the risk of aspiration pneumonia. ${ }^{13}$ Desaturation occurs faster in older patients hence preoxygenation should be done religiously. The time to peak relaxation following neuromuscular blockade is delayed with increasing age and the elderly are more prone to have a cardiac event from desaturation.

The pharmacokinetics and pharmacodynamics of drugs are also altered in geriatrics. The ED 50 equivalent for inhalational anesthetics falls linearly with age therefore, the dosage of drugs affecting central nervous system (CNS) need be reduced. Hypotension is very common so the dosages of agents like propofol, opioids, benzodiazepines, thiopentone etc. should be titrated as shown in Table 2.

Short acting drugs should be selected. Peak effects of drugs administered is delayed: midazolam 5 mins, fentanyl 6 to $8 \mathrm{~min}$, and for propofol 10 minutes. Autonomic neuropathy of diabetes, diminished gut motility and diminished hepatic functions makes geriatric patients vulnerable to side-effects of opioids and anaesthetic drugs. Aging of the autonomic nervous system shows limited adaptability to stress; decreased basal activity of the parasympathetic nervous system and overall net activation of the sympathetic nervous system; decreased baroreflex sensitivity; slowing and weakening of homeostatic functions. The increase in sympathetic tone in older patients should also be considered when choosing an anesthetic with sympathomimetic properties, as such anesthetics may be poorly tolerated by some individuals with cardiovascular disease.

\section{Neuraxial anesthesia}

Not only are there anatomical changes which affect neuraxial blockade in elderly, there are also several physiological factors. Age has no effect on duration of motor blockade with bupivacaine spinal anaesthesia 
although the time of onset is decreased. The LA spread is more extensive with hyperbaric bupivacaine because of the physiologic changes described in Table 1 . Studies have not revealed any effect of age on duration of epidural anesthesia. ${ }^{6}$

Table 2: Clinical pharmacology of anesthetic agents in elderly. ${ }^{6}$

\begin{tabular}{|llll|}
\hline Drug & Brain sensitivity & Pharmacokinetics & Dose \\
\hline Inhalational agents & Increased & $\leftrightarrow$ & Decreased \\
\hline Thiopentone & $\leftrightarrow$ & Decreased initial volume of distribution & Decreased \\
\hline Etomidate & $\leftrightarrow$ & Decreased initial volume of distribution & Decreased \\
\hline Propofol & Increased & Decreased clearance & Decreased \\
\hline Midazolam & Increased & Decreased clearance & Decreased \\
\hline Morphine & Increased & Decreased clearance & Decreased \\
\hline Fentanyl & Increased & $\leftrightarrow$ & Decreased \\
\hline Vecuronium & NA & Decreased clearance & Decreased \\
\hline Atracurium & NA & $\leftrightarrow$ & $\leftrightarrow$ \\
\hline Cisatracurium & NA & $\leftrightarrow$ & $\leftrightarrow$ \\
\hline
\end{tabular}

Table 3: Recommendations for anesthesia in some specific orthopedic surgeries. ${ }^{5}$

\begin{tabular}{|c|c|c|}
\hline Type of surgery & Technique of anesthesia & Advantages of regional anesthesia \\
\hline Hip fracture repair & $\begin{array}{l}\text { Discuss about the risk and benefit with the } \\
\text { patient and decide about regional or general } \\
\text { anesthesia!! }\end{array}$ & $\begin{array}{ll}\text { - } & \text { Reduced mortality } \\
\text { - } & \text { Reduced requirement of sedatives } \\
\text { - } & \text { Avoids airway instrumentation } \\
\text { - } & \text { Decreased blood loss } \\
\text { - } & \text { Decreased risk of thrombosis } \\
\text { POCD }\end{array}$ \\
\hline $\begin{array}{l}\text { Elective hip and knee } \\
\text { arthroplasty }\end{array}$ & Consider regional anesthesia & $\begin{array}{l}\text { - } \\
\text { - } \text { Beduced mortality } \\
\text { sedation } \\
\text { - Reduced systemic infection and less use } \\
\text { of critical care }\end{array}$ \\
\hline
\end{tabular}

The anatomical changes pose as challenges for neuraxial blockade technique. ${ }^{14}$ It is not uncommon to find dorsal kyphosis, osteoarthritic and rheumatoid arthritic changes limiting range of motion of the spine, osteoporosis further decreasing mobility and difficult needle placement. There is difficulty in positioning due to above mentioned reasons along with degenerative changes of intervertebral disc and vertebrae and compression of intervertebral and epidural spaces. There occurs calcification of ligamentum flavum and other ligaments making needle placement more challenging. Osteophytes decrease the size of the intervertebral space, which limits access to the subarachnoid space. By using lateral or paramedian needle approach, we can avoid calcified vertebral midline ligament and distortion of dorsal vertebrae. The L5-S1 interspace, the largest intervertebral space can ease the blockade in severe osteoarthritis patients.

\section{General vs regional anesthesia}

There is no clear cut evidence of which type of anesthesia is preferred in elderly. Both types have their own pros and cons. Memtsoudis et al have said that regional anaesthesia has advantages of reduced blood loss during surgery and decreased need for transfusion and related hazards, decreased incidence of deep-vein thrombosis and pulmonary embolism, better postoperative analgesia and lesser costs, all important considerations during geriatric anaesthesia. ${ }^{15}$

Whereas Waesberghe et al have said that they could not detect any difference in the 30-day mortality in patients undergoing hip fracture surgery. However, in their study, the length of hospital stay and the in-hospital mortality were significantly shorter in the neuraxial anaesthesia group. The incidence of myocardial infarction and respiratory failure was significant lower in the neuraxial anaesthesia group and there was no difference in the incidence of pneumonia between the two groups. They also found that spinal anaesthesia may be associated with significantly reduced early mortality, fewer incidents of deep vein thrombosis, less acute postoperative confusion, a tendency to fewer myocardial infarction, fewer cases of pneumonia, fatal pulmonary embolism and postoperative hypoxia. In their meta-analysis they did not observe any difference in the 30-day mortality rate between neuraxial and general anaesthesia although length of hospital stay and the in-hospital mortality was shorter in the neuraxial anaesthesia group. ${ }^{16}$

As per the American Geriatric Society guidelines, in Table 3 we see the recommendations for technique of 
anesthesia in some specific orthopedic surgeries and the advantages of regional anesthesia. ${ }^{5}$

There is evidence that the use of regional techniques allows for the minimization or elimination of the negative side effect profiles of other systemic pain management options, such as bowel and bladder dysfunction, hemodynamic derangements, and cognitive effects often experienced with opiates and other analgesic adjuncts and sedative or hypnotics, to which older patients are often more sensitive. ${ }^{14}$ The type of anesthesia should be decided by a multidisciplinary approach, patient, attendants, type of surgery, comorbidities and weighing the risk versus benefit ratio. Further studies are still required to decide which type is better.

\section{Post operative management}

In elderly patients postsurgical stress, both physical and psychological leads to an imbalance in autonomic, endocrine, metabolic, and immune functions. Depending on the patient's preoperative physiologic reserve and comorbid conditions, additional clinical challenges may impose further alterations in the stress response and the recovery trajectory. ${ }^{17}$ Common postoperative complications in elderly include delirium, pulmonary complications, falls, undernutrition, urinary tract infection, pressure ulcers, and functional decline.

\section{Postoperative cognitive dysfunction and delirium}

Postoperative cognitive dysfunction (POCD) refers to a deterioration in cognition temporally associated with surgery as quantified by neuropsychological tests. Although all orthopedic surgeries in elderly are a risk factor for development of POCD or delirium, patients with hip fractures have a high incidence of post-operative delirium of 32 to $53.3 \%$ due to physiological and psychological stress from injury, pain, analgesia and surgery. ${ }^{16}$ Anesthetic technique is a potentially adjustable risk factor for postoperative delirium. Unfortunately, most studies have been unable to detect a consistent difference in postoperative delirium between regional and general anesthesia. ${ }^{18-20}$ Marcantonio and colleagues developed a risk factor criteria for development of POCD in general, orthopaedic, and gynaecology surgery. ${ }^{21}$ The risk factors were: age $>70 \mathrm{yr}$, alcohol abuse, poor cognitive status, poor functional status, markedly abnormal sodium, potassium, or glucose, non-cardiac thoracic surgery, aortic aneurysm surgery, with one point given to each risk factor. 0 points, $<1 \% ; 1$ point, $8 \% ; 2$ points, $19 \%$; and 3 points, $45 \%$.

To prevent POCD or delirium post operatively, we should provide adequate pain control, optimize physical environment (for example, sleep hygiene, sleep protocol, minimize tethers, encourage family at bedside), make vision and hearing aids accessible, remove catheters, minimize psychoactive medications, and avoid potentially inappropriate medications. ${ }^{22}$

\section{Respiratory complications}

Older adult patients are at risk for postoperative pulmonary complications, including atelectasis, hospital acquired pneumonia, and acute respiratory failure. These kinds of complications increase the risk of long-term mortality following surgery. Additionally, older age may be an independent predictor of postoperative pneumonia, after adjustment for comorbidity burden. ${ }^{23}$ To avoid postoperative respiratory complications several measures can be taken. Epidural analgesia techniques should be used whenever possible. Intermediate (like cisatracurium, rocuronium, vecuronium) and long acting neuromuscular blocking agents (like pancuronium) should be avoided. When neuromuscular blockade is used, adequate recovery of neuromuscular function prior to extubation should be ensured. Preoperative incentive spirometry and deep breathing exercises should been started as already mentioned. Early mobilization and ambulation should be done and aspiration precautions should be taken.

\section{Thromboembolism}

Increasing age is a known risk factor for thromboembolism. ${ }^{3}$ Other risk factors which may add up to the list are surgery, trauma, immobility, lower extremity paresis all of which may be found in orthopedic patients. Prophylaxis to prevent venous thromboembolism (VTE) should be taken whenever possible. the elderly should be put on intermittent pneumatic compression devices on a priority basis during and after prolonged orthopedic surgeries.

In case 2, the patient was on aspirin and clopidogrel. As per the American Society for Regional Anesthesia (ASRA) guidelines for aspirin- "in patients receiving these medications, we do not identify specific concerns as to the timing of single-injection or catheter techniques in relationship to the dosing of NSAIDs, postoperative monitoring, or the timing of neuraxial catheter removal". 3 The ASRA guidelines for clopidogrel "based on labeling and surgical/procedural experience, the recommended time interval between discontinuation of thienopyridine therapy and neuraxial blockade is 5-7 days for clopidogrel". ${ }^{3}$ Since it was an emergency case, we opted for general anesthesia rather than regional anesthesia to bypass the waiting time required to give neuraxial blockade.

\section{TO PERFORM SURGERY OR NOT?}

Following are some of the studies which force us to think that "do we need surgery or not?"

Most hip fractures in patients over 100 years of age are pertrochanteric. Patients with 2 or more major background diseases have an increased risk for dying in the first 6 months after the operation. Most patients having operations in this age group had a postoperative reduction in mobility status and in performing basic 
activities of daily living. ${ }^{24} \mathrm{~A}$ significantly higher 30 -day and 1-year mortality was revealed in nonoperatively treated hip fracture patients. ${ }^{25}$ Operating on patients older than 100 years carries an acceptable mortality rate. Age alone should not preclude centenarians from undergoing operative treatment for hip fractures. ${ }^{26}$ The ability to remain independent is vital to many elderly patients as highlighted in a study by Salkeld et al, where $80 \%$ of elderly female patients stated that they would rather die than lose their independence and be admitted to a nursing home establishment. ${ }^{27}$

A multitude of factors influence the surgical outcomes in older patients, such as the type, duration, and invasiveness of an operation, coexisting medical or mental status dysfunction, and the skill and expertise of both the anesthesiologist and surgeon hence eventually it has to be a combined decision of the patient, attendants, the concerned physician, orthopedic surgeon and the anaesthesiologists to weigh the risk vs benefit ratio of whether the patient should be managed conservatively, where possible, or to go ahead with surgery. ${ }^{5}$

\section{CONCLUSION}

A multidisciplinary approach is required for perioperative management of geriatric orthopaedic cases. As our population continues to age, anesthesiologists and surgeons are tasked with identifying anesthetic techniques that minimize morbidity and mortality and postoperative cognitive disorders in the older patient, in our case we discussed three patients over the age of 100 years. To conclude we would say that age is just a number and every patient needs to be individualised according to the comorbidities, type and duration of surgery, expected complications thus deciding about the anesthesia technique hoping for the best but preparing for the worst. As of the year 2020, if you are not a pediatric, you are a geriatric specialist!

Funding: No funding sources Conflict of interest: None declared

Ethical approval: Not required

\section{REFERENCES}

1. Baek GH. Are we prepared for geriatric orthopedics?. Clin Orthop Surg. 2010;2(3):129.

2. Taha AM, Ghoneim MA. Hip Arthroplasty using major lower limb nerve blocks: A preliminary report of a case series. Saudi J Anaesth. 2014;8:355-8.

3. Horlocker TT, Vandermeuelen E, Kopp SL, Gogarten W, Leffert LR, Benzon HT. Regional Anesthesia in the Patient Receiving Antithrombotic or Thrombolytic Therapy: American Society of Regional Anesthesia and Pain Medicine EvidenceBased Guidelines (Fourth Edition). Reg Anesth Pain Med. 2018;43(3):263-309.
4. Sivevski AG, Karadjova D, Ivanov E, Kartalov A. Neuraxial Anesthesia in the Geriatric Patient. Front Med (Lausanne). 2018;5:254.

5. Mohanty S, Rosenthal RA, Russell MM, Neuman MD, Ko CY, Esnaola NF. Optimal Perioperative Management of the Geriatric Patient: A Best Practices Guideline from the American College of Surgeons NSQIP and the American Geriatrics Society. J Am Coll Surg. 2016;222(5):930-47.

6. Berger A, Acker L, Deiner S. Geriatric Anesthesia. In Ronald D. Miller's Miller's Anesthesia, 9th edition, Philadelphia, PA: Churchill Livingstone, Elsevier; 2019; 2102-2114.

7. Lobo DN. Fluid overload and surgical outcome: another piece in the jigsaw. Ann Surg. 2009;249(2):186-8

8. LacKamp A, Seiber F. Physiologic Response to Anesthesia in the Elderly. In: Rosenthal R, Zenilman M, Katlic M, eds. Principles and Practice of Geriatric Surgery. New York: Springer; 2011: 300.

9. Pennestrì F, Maffulli $\mathrm{N}$, Sirtori $\mathrm{P}$, Perazzo $\mathrm{P}$, Negrini F, Banfi G, et al. Blood management in fasttrack orthopedic surgery: an evidence-based narrative review. J Orthop Surg Res. 2019;14:263.

10. Leme LE, Sitta Mdo C, Toledo M, da Silva Henriques S. Orthopedic surgery among the elderly: clinical characteristics. Rev Bras Ortop. 2015;46(3):238-46.

11. Amin NH, West JA, Farmer T, Basmajian HG. Nerve Blocks in the Geriatric Patient With Hip Fracture: A Review of the Current Literature and Relevant Neuroanatomy. Geriatr Orthop Surg Rehabil. 2017;8(4):268-75.

12. Johnson KN, Botros DB, Groban L, Bryan YF. Anatomic and physiopathologic changes affecting the airway of the elderly patient: implications for geriatric-focused airway management. Clin Interv Aging. 2015;10:1925-34.

13. Achem SR, DeVault KR. Gastroesophageal reflux disease and the elderly. Gastroenterol Clin North Am. 2014;43(1):147-60.

14. Perioperative regional anesthesia elderly. Available at: https://www.nysora.com/foundations-of-regional -anesthesia/sub-specialties/elderly/perioperativeregional-anesthesia-elderly/. Accessed on 3 June 2019.

15. Luger TJ, Kammerlander C, Gosch M, Luger MF, Kammerlander-Knauer U, Roth T, et al. Neuroaxial versus general anaesthesia in geriatric patients for hip fracture surgery: Does it matter? Osteoporos Int 2010;21(4):555-72.

16. Van Waesberghe J, Stevanovic A, Rossaint R, Coburn M. General vs. neuraxial anaesthesia in hip fracture patients: a systematic review and metaanalysis. BMC Anesthesiol. 2017; 17:87.

17. Wilmore DW. From Cuthbertson to fast-track surgery: 70 years of progress in reducing stress in surgical patients. Ann Surg. 2002;236(5):643-8 
18. Atay IM, Aslan A, Atay T. Prevalence of delirium, risk factors and cognitive functions in elderly hip fracture patients with general and spinal anesthesia. Turk Geriatri Dergisi. 2012;15(3):273-8.

19. Bryson GL, Wyand A. Evidence-based clinical update: general anesthesia and the risk of delirium and postoperative cognitive dysfunction. Can J Anaesth. 2006;53(7):669-77.

20. Berger M, Schenning KJ, Brown $\mathrm{CH}$ 4th, Deiner SG4, Whittington RA5, Eckenhoff RG, et al. Best Practices for Postoperative Brain Health: Recommendations From the Fifth International Perioperative Neurotoxicity Working Group. Anesth Analg. 2018;127(6):1406-13.

21. Marcantonio ER, Goldman L, Mangione CM, Ludwig LE, Muraca B, Haslauer CM, et al. A clinical prediction rule for delirium after elective noncardiac surgery. JAMA. 1994;271:134-9.

22. The 2019 American Geriatrics Society Updated Beers Criteria ${ }^{\circledR}$ for Potentially Inappropriate Medication Use in Older Adults. Journal of the American Geriatrics Society, 2019.

23. Qaseem A, Snow V, Fitterman N, Hornbake ER, Lawrence VA, Smetana GW, et al. Risk assessment for and strategies to reduce perioperative pulmonary complications for patients undergoing noncardiothoracic surgery: a guideline from the American College of Physicians. Ann Intern Med. 2006;144(8):575-80

24. Shabat S, Mann G, Gepstein R, Fredman B, Folman $\mathrm{Y}$, Nyska M. Operative treatment for hip fractures in patients 100 years of age and older: is it justified?. J Orthop Trauma. 2004;18(7):431-5.

25. van de Ree CLP, De Jongh MAC, Peeters CMM, de Munter L, Roukema JA, Gosens T. Hip Fractures in Elderly People: Surgery or No Surgery? A Systematic Review and Meta-Analysis Geriatr Orthop Surg Rehabil. 2017;8(3):173-80.

26. Tarity TD, Smith EB, Dolan K, Rasouli MR, Maltenfort MG. Mortality in centenarians with hip fractures. Orthopedics. 2013;36(3):282-7.

27. Salkeld G, Cameron ID, Cumming RG, Easter S, Seymour J, Kurrle SE, et al. Quality of life related to fear of falling and hip fracture in older women: a time trade off study. BMJ. 2000;320(7231):341-6

Cite this article as: Krishna B, Pathak N. Perioperative management of geriatric patients for orthopedic surgeries. Int J Res Orthop 2020;6:42734 